\title{
BIFURCATION OF SUPERIOR ARTICULAR FACETS OF ATLAS VERTEBRA: A CASE STUDY IN DRY BONES
}

\author{
SMRUTI REKHA MOHANTY, MAMTA PANIGRAHI, SUSMITA SENAPATI*, SAMAL SN
}

Department of Anatomy, Kalinga Institute of Medical Sciences, Bhubaneswar, Odisha, India. Email: susmitashashi@gmail.com

Received: 10 September 2021, Revised and Accepted: 18 December 2021

ABSTRACT

Objective: The objective of the study was to see the superior articular facets (SAF) of atlas vertebrae for complete bifurcation.

Methods: In a number of 50 atlas vertebrae with 100 SAF were studied for the tendency to complete separation in the Department of Anatomy and Forensic Medicine of Kalinga Institute of Medical Sciences, Bhubaneswar during the period of January 2015 to January 2016.

Results: Out of 50 atlas vertebrae (100 AF), we observed complete bifurcation on both sides in 14 atlas vertebrae (28 sides) and complete bifurcation right side only in six atlas vertebrae and complete bifurcation left side only in 14 atlas vertebrae. The results were compared with those of other studies and were statistically analyzed.

Discussion: The clinical significance of this study has been thus discussed with a reference to its possible effect on the restriction of the neck movement at the atlanto-occipital joint.

Conclusion: This study is of great importance to the clinicians for doing any clinical facet procedure in the neck region.

Keywords: Atlas, Bifurcation, Groove, Presence of constriction, Superior articular facet.

(C) 2022 The Authors. Published by Innovare Academic Sciences Pvt Ltd. This is an open access article under the CC BY license (http://creativecommons.org/ licenses/by/4.0/) DOI: http://dx.doi.org/10.22159/ajpcr.2022v15i2.43101. Journal homepage: https://innovareacademics.in/journals/index.php/ajpcr

\section{INTRODUCTION}

The atlas (C1 vertebra) supports the globe of the head [1-3]. Anatomically, it is embedded in the neck muscles and is therefore protected from injury [4,5]. The unique structure and the anatomical location of the atlas form a safety mechanism. Superior articular facets (SAF) which are present on the atlas vertebrae are usually concave, face superomedially and are admirably accepted for nodding movements and also for the weight bearing of the head $[4,5]$. These are also accepted for the reception of the condyles of the occipital bone to form an atlanto-occipital joint. Thus, the assessment of these structures and the morphological relationship of the SAF of the atlas are done before performing any clinical procedure in its proximity [5]

Schaeffer described different shapes of the SAF as concave, deeply concave, oval, elongated, and kidney shaped [6]. Rare data are available about this specific type of variation of atlas. Variation in the shape of SAF of atlas may give rise to neurological and vascular symptoms. Furthermore, it may hamper the atlanto-occipital joint mobility [6].

Frank et al. in their study observed that bipartition of the SAF of atlas is a derived characteristic restricted to the human only. This could be due to some functional modifications during the process of evolution [7].

\section{METHODS}

The study was conducted in the Department of Anatomy and forensic medicine, Kalinga Institute of Medical Sciences, Bhubaneswar during the period January 2015 to January 2016. The material for the study comprised 50 adult human atlas vertebrae (100 SAF) of unknown age and sex. All the vertebrae are meticulously examined for the tendency of complete separation of SAF. Atlas vertebrae with damaged SAF were excluded from the study.

\section{RESULTS}

In 50 atlas vertebrae, the $100 \mathrm{SAF}$ were studied for the presence of complete separation. Based on these observations, the percentage was calculated excluding the partial partitions of the SAF. The readings were noted and the results were compared with the findings of other workers, as shown in the table.

Out of 50 atlas vertebrae (100 SAF), in 14 atlas vertebrae (28 SAF) were observed to have complete bifurcation, that is, $28 \%$ (Table 1 , Figs. 1 and 2). Out of 50 right sides SAF, six atlas vertebrae were observed to have only complete bifurcation, that is, $12 \%$ (Table 1 and Fig. 3). Out of 50 left side SAF, 14 were observed to have complete bifurcation, that is, $28 \%$ (Table 1 and Fig. 4).

\section{DISCUSSION}

Atlas is the $1^{\text {st }}$ cervical vertebra and also very important vertebra as it supports the globe of our head. The stability of the joint between the SAF of atlas and the occipital condyles depends on the congruence of the articular surfaces [4]. Hence, the present study is very important and rare literatures are available regarding the study of SAF.

Singh [8], in his study, found complete bilateral partition of SAF only in $5.5 \%$ cases but in the present study we found in $28 \%$ cases and also he found left sided predominance where as in our study we found the right sided predominance (Table 1).

Gottelib [9], in his study, found incidence of bilateral partition of SAF of atlas $28.6 \%$ which is equal to the present study but he also found the left sided predominance.

Hasebe, in his study, found 0 incidence of partition of SAF in Japanese population which shows a racial variation [10]. 


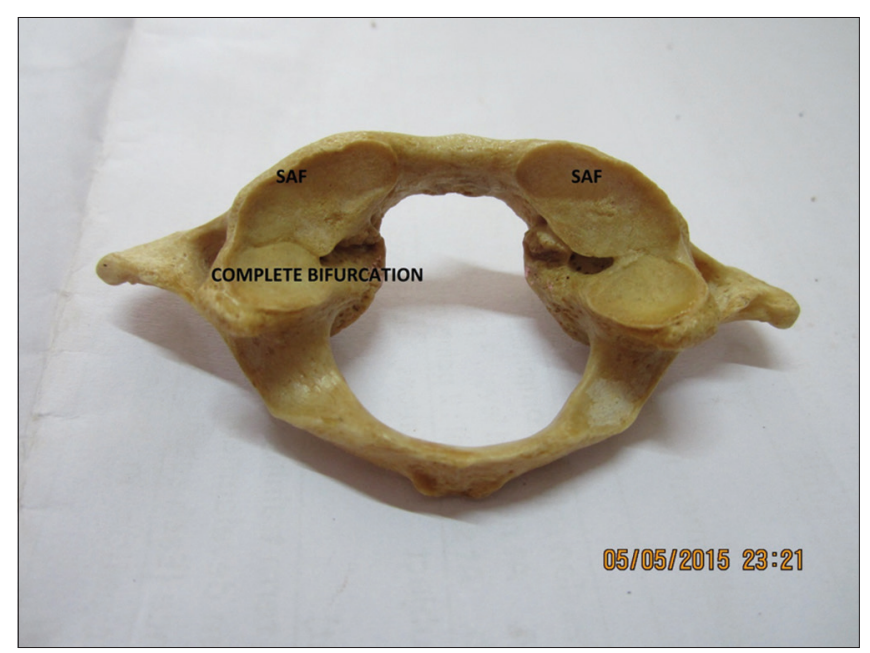

Fig. 1: Atlas vertebra showing bilateral complete bifurcation of the superior articular facet. SAF: Superior articular facet

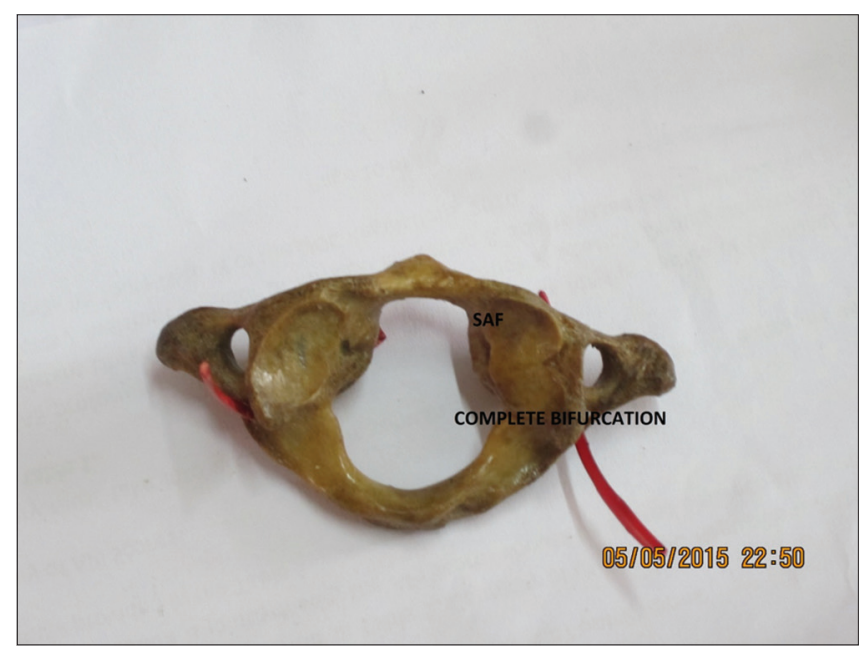

Fig. 2: Atlas vertebra showing complete bifurcation of the superior articular facet only on the right side. SAF: Superior articular facet

\section{Clinical importance}

- The tendency of the SAF of the atlas to split into two is an indication of restricted movements at the atlanto-occipital joint [5].

- Superior and inferior articular processes form a solid articular pillar that transmits some weight from one vertebra to the next lower vertebra. Abnormal hypertrophy of the $\mathrm{AF}$ is again a recognized cause for the narrowing of the vertebral canal and consequent neurological features [8].

- It is possible that extreme rotation movements at the cervical spine in an individual with an associated bony canal may result in the compression of the vertebral artery and compromised blood flow. Thus, these anatomical features should be taken into account in the therapeutic manipulation of the cervical spine $[1,8]$.

- The knowledge of the quantitative anatomy of the vertebral artery groove on the posterior arch of the atlas will prove useful to the surgeons who perform operative procedures in this region and will thus help in avoiding vascular complications $[2,11]$.

- In recent years, considerable innovations in the internal fixation techniques have created a need for a more detailed quantitative description of the anatomy of this bone [11].

- The anatomy of the cervical vertebrae or the spine is of high clinical importance to surgeons, as a surgical procedure maybe done through the anterior or posterior cervical spine with gratifying results [3-5].

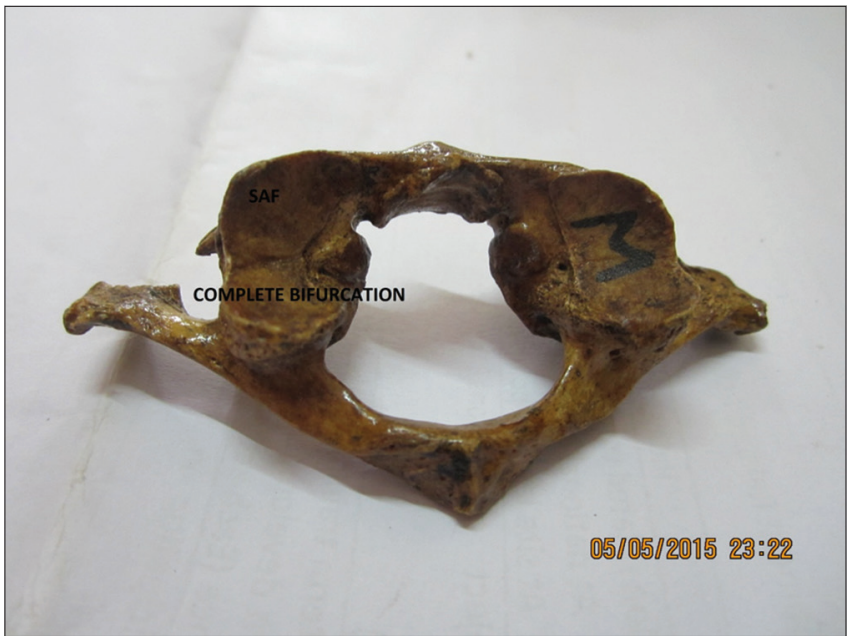

Fig. 3: Atlas vertebra showing complete bifurcation of the superior articular facet only on the left side. SAF: Superior articular facet

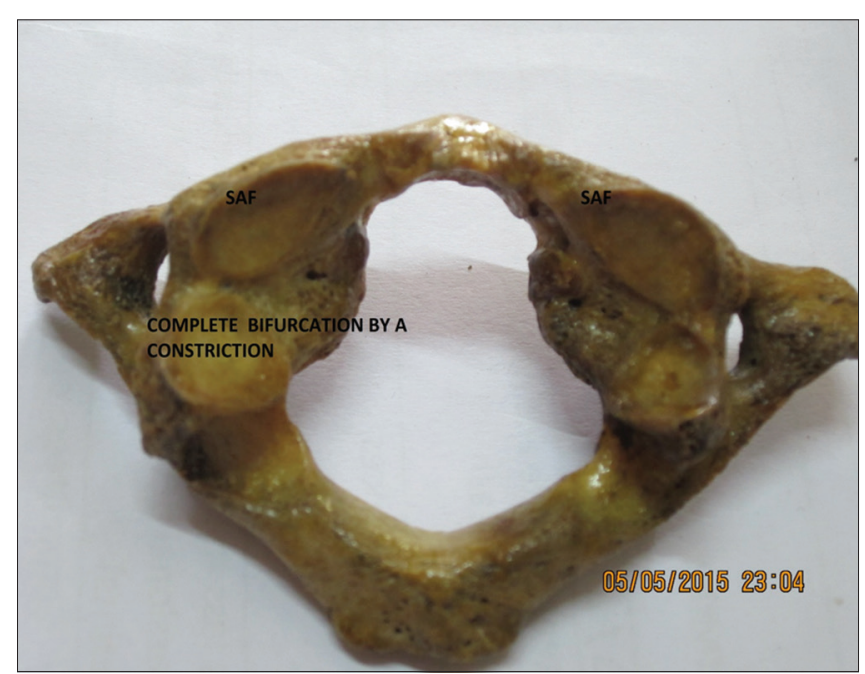

Fig. 4: Atlas vertebra showing bilateral complete bifurcation of the superior articular facet. SAF: Superior articular facet

Table 1: The results of bifurcation of SAF of atlas

\begin{tabular}{lll}
\hline Bilateral & Unilateral right & Unilateral left \\
\hline 14 (28 sides) & 6 & 14 \\
Incidence: $28 \%$ & 12 & 28 \\
\hline
\end{tabular}

SAF: Superior articular facet

Angulations of atlas, using mathematical applications, were reported in 20 fresh spine specimens with a significant difference between the ant-post to transverse dimensions on left side. These types of metric values are important in complications like Whiplash injury of cervical spine [12].

Paraskevas et al. reported an incidence of separation of SAF and that a decrease in constrictions could possibly be the result of a restriction in the atlanto-occipital motion in old age $[13,14]$.

The anatomy of atlas vertebra is very important for the surgeons and the present study is also of great importance in understanding the ergonomics of atlanto-occipital joint. 


\section{CONCLUSION}

In the present study, complete bifurcation of SAF of atlas was observed in $28 \%$, unilateral bifurcation only in the left in $12 \%$ and unilateral bifurcation only in the right side $28 \%$. This study is of great importance to surgeons, orthopedicians while doing any clinical procedures in this region.

\section{REFERENCES}

1. Bohlman HH. Acute fractures and dislocations of the cervical spine. J Bone Joint Surg 1979;61-A:1119-41.

2. William M, Newell RL, Collin P. The back: Cervical vertebrae. In: Standring S, Ellis H, Haely JC, Johson D, Williams A, editors. Gray's Anatomy. $39^{\text {th }}$ ed. Edinburg, London: Elsevier, Churchill Livingstone; 2005. p. 742-6.

3. Landells CD, Peteghem KV. Fractures of the atlas: Classification, treatmentand morbidity. Spine (Phila Pa 1976) 1988;13:450-2.

4. Bryce TH. Osteology the skeleton-vertebral calumn. In: Schaffer EA, Symington J, Bryce TH, editors. Quains Elements of anatomy. $11^{\text {th }}$ ed. London: Longmans Green and Co.; 1915. p. 5-34

5. Grant JC. Cervical vertebrae. In: An Atlas of Anatomy by Regions. $2^{\text {nd }}$ ed. Baltimore, USA: The Williams and Wilkins Company; 1948. p. 268-74.
6. Schaeffer JP. Morris's Human Anatomy, A Complete Systematic, Treatise. $10^{\text {th }}$ ed. United States: Creative Media Partners, LLC; 1942. p. 85 .

7. Frank B, Marie LM, Steinwachs M. Bipartition of the superior articular facets of the $1^{\text {st }}$ cervical vertebra (atlas or $\mathrm{C} 1$ ): A human variant probably specific among primates. Ann Anat 2007;189:79-85.

8. Singh S. Variations of the superior articular facets of the atlas vertebrae. J Anat 1965;99:565-71

9. Gottelib MS. Absence of symmetry in superior articular facets on the first cervical vertebra in humans: Implications for diagnosis and treatment. J Manipulative Physiol Ther 1994;17:314-20.

10. Hasebe K. Die wirbelsaule der Japaner. Z Morphol Anthropol 1913;15:259-380.

11. Francis CC. Variations in the articular facets of the cervical vertebrae. Anat Rec 1955;122:589-602.

12. Scheuer L, Black S. Developmental Juvenile Osteology. Amsterdam: Elsevier; 2000. p. 199

13. Paraskevas G, Papaziogas B, Tzeveas A, Natis K, Spanidou S, Kitsoulis P. Morphological parameters of the superior articular facets of atlas and potential clinical significance. Surg Radiol Anat 2008;30:611-7

14. Motagi MV, Ranganath V. Morphometric analysis of superior articular facets of atlas vertebra and its clinical applications in ergonomics of atlanto-occipital joints. J Clin Diagn Res 2013;7:2674-6. 